\title{
The Influence of Ethnic Affiliation on Preference for Inter-Ethnic Interactions Among Undergraduate in Lagos Nigeria
}

\author{
Kehinde O. Ayenibiowo \\ Department of Psychology \\ University of Lagos \\ Gabriel A. AKINBODE \\ Department of Psychology \\ University of Lagos \\ bodegabriel@yahoo.com
}

\begin{abstract}
The study investigates preference for inter-ethnic relationship as a function of ethnic affiliation among undergraduate students in University of Lagos, Nigeria. The sample for the study comprises of 684 undergraduates 284 of them were male while 400 were female with age range of between 18 to34 years. A questionnaire on preference for interaction with persons from various ethnic groups in Nigeria was designed and administered to assess respondents' willingness to interact with persons of the diverse ethnic groups at various levels of intimacy. Data collected was analyzed using frequencies and Chisquare The result revealed the prevalence of two major ethnic groups (Yoruba and Igbo) among the respondents. Chi-square analysis of the results shows that more of the participants from each of these two groups prefer to relate with members of their own ethnic group than members of the other ethnic groups. Logistic regression further revealed that young adults were more tolerant of other ethnic groups than their old adult's counterparts. Similarly, males reported more tolerance to ethnic differences compared to their female counterparts. Also, Yoruba participants were more tolerant to other ethnic groups compared to both Igbo's and the other ethnic groups. However there is gender difference in spousal preference such that more male than female preferred inter-ethnic marriages while the reverse was the case for intraethnic marriages. This finding is attributed to patriarchy which is prevalent in the country. However, for less intimate relationships, a substantial number prefer inter-ethnic relationships.
\end{abstract}

Key words: Ethnic affiliation, Interpersonal relationship. Inter-ethnic Preferences, Patriarchy

\section{INTRODUCTION}

Ethnic affiliation is one of the major characteristics of persons in multi-ethnic society, where interpersonal interaction is more or a norm among young and old (Clore \& Byrne, 1974; Kelley, et al, 1983; Afifi \& Metts, 1998; Felmlee \& Muraco, 2009; Cupach \& Carson, 2012). Nigeria as a typical multi-ethnic nation has been faced with issues of ethnic clashes, misunderstanding and suspicion. In an attempt to eradicate these vices and foster unity, the government has in the past introduced policies and institutions that encourage interactions of youths from the diverse ethnic groups. Prominent among these are establishment of Federal Secondary Schools and universities and the National Youth Service Corp whereby graduates serve outside their 
states of origin. All these are avenues for youths to interact and appreciate the various ethnic groups thus fostering unity. In order to evaluate the potential for reducing the boundaries and social distances between the peoples of various ethnic groups, it is important to have a clear sense of the level of inter-ethnic friendship and the attitudes that Nigerian citizens have about broadening and deepening them. Relationships run right through everyday life, and for this reason everyone is interested in how relationships work and how to make them work better. Paradoxically, study of relationships is difficult because taken-for-granted assumptions make it hard to stand back and think about how they work.

The importance of relationships, both sexual and non-sexual, is 'obvious', particularly when friendship network, characteristics and psychological wellbeing in late adolescence is of great concern (Almquist, et al 2014). According to Duck (1999), we need merely to reflect for a moment on the sources of our greatest pleasure and pain to appreciate that nothing else arouses the extremes of emotion that are experienced in the course of personal relationships with other human beings Relationships make life meaningful, whether they are good or bad. Most relationship research has focused on 'voluntary' relationships. When describing relationships breaking up (or down), we often use language that implies a degree of choice. Traditionally, social psychologists have been interested in interpersonal attraction, which relates to the question: 'How do relationships start?' But during the last 20 years or so, the emphasis has shifted to relationships as a process (Duck, 1999), reflected in two further questions: 'What makes people stay in relationships (maintenance and progression)?' and 'Why and how do relationships go wrong (breakdown or dissolution)? Affiliation is the basic human need for the company of other human beings. The need to belong and to be accepted by others is one of Maslow's basic survival needs, and is also a major motive underlying conformity.

Conformity can be explained in terms of the need to evaluate our beliefs and opinions by comparing them with other people's, especially in ambiguous or unstructured situations. This is the central idea in Festinger's (1954) social comparison theory. According to Duck (1988), we are more 'affiliative' and inclined to seek others' company under certain conditions than others, for example, when we are anxious, when we have just left a close relationship, and when we have moved to a new neighbourhood. Anxiety is one of the most powerful factors. Kulik and Mahler (1989) reached the same conclusions when studying patients about to undergo coronary-bypass surgery. Most preferred to share a room with someone who had already undergone coronary surgery, rather than another patient waiting for the same operation. The main motive for this preference seemed to be the need for information about the stress-inducing situation. Not only were those assigned a post-operative roommate less anxious, they were more mobile post-operatively and had faster post-operative recoveries (Kulik et al., 2003).

\section{The Problem}

The government of Nigeria in the past has envisaged the need for ethno-religious tolerance and so institute policies and avenues for youths to interact and appreciate the various ethnic groups thus fostering unity. The core objective of such policies across the globe was to reduce inter-ethnic boundaries and social distances between the peoples of various ethnic groups (Kelly, et al, 1983; Neziek, 1995; Holmes, 2000; Felmlee, 2001; Argyle, 2002). Be that as it may, Nigeria is a multiethnic society where little is currently known about how, young people mix with friends from different ethnic backgrounds and the potential impact of this on attitudes and preferences for a long lasting inter-personal interaction. The recent spate of inter-ethnic 
intolerance, ethno-religious conflicts, inter-ethnic rivalries and Boko haram insurgency, is suspected implications of the level of ethnic intolerance in the country. Therefore, it has become a matter of utmost importance to have a clear sense of the level of inter-ethnic friendship and the attitudes of Nigerian citizens towards themselves. Relationships run right through everyday life, and for this reason everyone is interested in how relationships work and how to make them work better (Argyle \& Furnham, 1983; Berscheid \& Reis, 1998; Berscheid \& Amazzalorso, 2004; Fujino, 1997).

Paradoxically, the question that bothers the mind of concerned researchers is that of "whether the intolerance is a matter of recent development or it has always been with us". It is worthy of note that Nigeria is a multiethnic society, unfortunately little or nothing is currently known about and how, young people mix with friends from different ethnic backgrounds and the potential impact of this on attitudes and preferences for a long lasting inter-personal interaction. The government of Nigeria, probably envisaging the grave implication of multiethnic status of the country and the need to tolerate one another through mutual understanding and interaction instituted one year National Youth Service Corp (NYSC). During this one year of national service as it is popularly referred to, young people are posted to different ethnic and cultural settings, where opportunity will be created to appreciate the culture and ethnic differences in the country. Whether this programme or policy is a success or not in the light of current spate of high level inter-ethnic intolerance has left more questions than answers. This paper explores the links between young People's interethnic friendships and their preferences patterns and behaviours. The study examines these links using quantitative and qualitative methods among a sample of young adults in the University of Lagos.

\section{Objectives of the Study}

○ To examine the pattern of ethnic affiliations and interpersonal interactions among young adults.

○ To examine the pattern of inter-ethnic preferences in choice of mates for inter-personal interaction.

- To investigate the influence of ethnic affiliations of young adult preferences for interethnic interaction.

\section{Significance of the Study}

The paper therefore carefully provides baseline data for achieving the following:

- Exploration of the intra- and interethnic mix of young people's friendship groups as described by young people themselves.

- Provision of empirical data on patterns ethnic preferences in interpersonal interaction.

○ Establishing the link between young people's background characteristics, their friendship groups (including the ethnicity of friends) and their reported preferences.

- Identification of the implications of the findings, including recommendations for interethnic tolerance, harmed insurgency reduction based on education and peer support programmes.

- Provision of a benchmark for a comprehensive appraisal of objectives of the National Youth Service Corps (NYSC).

\section{Research Questions}

- What is the pattern of ethnic affiliations and interpersonal interactions among young adults of Yoruba, Igbo and other ethnic groups in Nigeria?

o What is the pattern of inter-ethnic preferences in choice of mates for inter-personal interaction? 
○ Will ethnic affiliations of young adult influence preferences for inter-ethnic interaction.

\section{Interpersonal Attraction: Theoretical Underpinning}

A general theoretical framework for explaining initial attraction is reward theory (Clore and Byrne, 1974; Lott \& Lott, 1974). The more rewards someone provides for us, the more we should be attracted to that individual. A number of factors have been found to influence initial attraction through their reward value, including proximity, exposure and familiarity, similarity and physical attractiveness.

Proximity: physical closeness or propinquity represents a minimum requirement for attraction: the further apart two people live, the lower the probability they will ever meet, let alone become friends or marry. Festinger et al. (1950) studied friendship patterns in a university campus housing complex for married students. People were friendlier with those who lived next door, next most friendly with those living two doors away, and least friendly with those who lived at the end of the corridor. On any one floor, people who lived near stairways had more friends than those living at the end of a corridor. However, physical proximity has become less important with the creation and expansion of Internet dating sites, chat rooms and email. It's much easier now to become friends, even lovers, with individuals at great geographical distance (Buunk and Dijkstra, 2008).

Exposure and familiarity: Proximity increases the opportunity for interaction (exposure), which, in turn, increases familiarity. There is considerable evidence that, far from breeding contempt, familiarity breeds fondness (the mere exposure effect: Zajonc, 1968). For example, the more times university students saw photographs of men's face, the more they liked them (Zajonc, 1968). According to Argyle (1983), the more two people interact, the more polarised their attitudes towards each other become - usually in the direction of greater liking. This, in turn, increases the likelihood of further interaction, but only if the interaction is on an equal footing. People form friendships with those they encounter frequently (as the mere exposure effect would predict). Asian Americans date Euro-Americans when they are in close proximity (Fujino, 1997), high-school students form friendships within their own academic subjects (Kubitschek and Hallinan, 1996), and older, relocated adults make friends among their nearest neighbours (Dugan and Kivett, 1998; Felmlee, 2001). According to Fiske (2004), if someone resembles prior experience or the self, then at least we have the illusion of knowing 'what makes them tick'. In this respect, familiarity and similarity influence attraction in comparable ways.

We mostly seek out others who make us feel good about ourselves: People who resemble us or agree with us also reassure us. People who validate us and like us presumably won't do us any harm (Fiske, 2004). According to the similarity-attraction principle, if familiarity underlies attraction, and if the most familiar people are those who are like us, then people like us are attractive. This stems in part from consistency theories of attitude change ; the most relevant here is Heider's (1958) balance theory. We prefer and infer affective, cognitive and behavioural consistency - in ourselves and others: we like to agree with our friends and to befriend those who agree with us. This describes interpersonal balance, 'a harmonious state, one in which the entities comprising the situation and the feelings about them fit together without stress' (Heider, 1958).

Another theoretical explanation is provided by the filter model (Kerckhoff \& Davis, 1962). The theory argued that relationships go through a series of filters, which are important if the relationship is to begin or progress. The more important the relationship is, the more effort and filtration. One of the most important selections is of our friends and partners. Relationships go though stages whereby 
different criteria are used at successive stages. It starts with social variables, such as class and religion. Then it moves to internal values. Finally, it moves to personality traits. Note that we seek similarity in social variables and values, but personality traits may be complementary. The first filter revolves around the fact that we only meet a very small fraction of people living in our area (proximity filter). Most of those we meet tend to be of a similar social class, education level and maybe even the same ethnicity or racial group (similarity filter). The third filter is based on psychological factors. The chances of a short term relationship becoming more permanent depended most on shared beliefs and values. The fourth filter surrounds our emotional needs as the best predictor of relationship survival.

According to this filter model (i) Similarity of sociological (or demographic) variables determines the likelihood of individuals' meeting in the first place. To some extent, our choice of friends and partners is made for us; social circumstances reduce the 'field of availables' (Kerckhoff, 1974) - that is, the range of people that are realistically (as opposed to theoretically) available for us to meet. There is considerable pre-selection of the types of people we come into contact with, namely, those from our own ethnic, racial, religious, social class and educational groups; these are the types of people we tend to find most attractive initially, since similarity makes communication easier and we have something immediately in common with them. At this point, attraction has little to do with other people's individual characteristics (this is the first 'filter'). (ii) The second filter involves individuals' psychological characteristics, specifically agreement on basic values. This was found to be the best predictor of the relationship becoming more stable and permanent. (iii) The third filter involves complementarity of emotional needs, which was the adjudged best predictor of a longer term commitment. Complementary behaviours take account of each other's needs, helping to make a perfect whole and making the relationship feel less superficial (Duck, 1999). The Stimulusvalue-role theory (Murstein, 1987) also provides another perspective to how relationship gets started. According to Murstein's Stimulus-Value-Role (SVR) theory, intimate relationships proceed from: (i) a stimulus stage, in which attraction is based on external attributes (such as physical appearance), through (ii) a value stage, in which similarity of values and beliefs becomes much more important, and finally to (iii) a role stage, which involves a commitment based on successful performance of relationship roles, such as husband and wife. Although all three factors have some influence throughout a relationship, each one assumes greatest significance during one particular stage.

\section{LITERATURE REVIEW}

According to Berscheid and Ammazzalorso (2004), the concept of a relationship: refers to two people whose behaviour is interdependent in that a change in behaviour in one is likely to produce a change in behaviour of the other A 'close' relationship denotes an interaction pattern that takes place over a long period of time; the partners' influence on each other is strong and frequent, and many different types of behaviour are affected (Kelley et al., 1983). In common with other close relationships, romantic relationships involve interdependence, strong feelings, committed intent and overlapping self-concept. But unique to romantic relationships are passion and exclusive commitment (Fiske, 2004). According to Moghaddam et al. (1993), interpersonal relationships in western cultures tend to be individualistic, voluntary and temporary; those in non-western cultures are more collectivist, involuntary and permanent.

Argyle and Henderson (2014) conducted four studies on the rules of friendship. Studies 1 and 2 established the strength of endorsement of 43 friendship rules in British, Italian, Hong Kong and Japanese samples. Study 3 found differences in reported rule-keeping between sustained and lapsed friendships by self and other, and between sustained relationships rated high and low in quality. Study 4 examined the role of rule breaking in friendship breakdown, and 
dissolution of friendship was attributed to the breaking of a number of our endorsed rules. Six rules were endorsed as very important in Study I and distinguished between behaviour in lapsed and current friendships; also relationship breakdown was related to failure to keep to these rules. They dealt mainly with the exchange of rewards and intimacy. Dissolution of friendships was also attributed to the breaking of third party rules.

Jeffrey (2012) in a multi-study investigation of friendship standards, the dimensions of ideal expectations identified and confirmed the factor structure of ideal friendship standards. Study 1 conducted an exploratory factor analysis on 30 existing subscales of friendship expectations. Study 2 reduced 181 items from past subscales and single-item measures of friendship expectations to 51 items measuring six factors. Study 3 used an international internet sample to conduct a confirmatory factor analysis on the six factor model. Samples from studies 2 and 3 were combined and factorial invariance was demonstrated by sample, by participant sex, and by age. The six factors of expectations (i.e., symmetrical reciprocity, agency, enjoyment, instrumental aid, similarity, and communion) constitute the ideal standards of friendship.

Jeffrey (2011) in a similar study investigated sex differences in friendship expectations. The study contends that friendship expectations are prescriptive normative behaviours and highly valued qualities in ideal same-sex friends. The paper reports the results of five meta-analyses of sex differences from 37 manuscripts. A small difference favouring females was detected in overall friendship expectations. Friendship expectations were higher for females in three of four categories: symmetrical reciprocity (e.g., loyalty, genuineness), communion (e.g., selfdisclosure, intimacy), and solidarity (e.g., mutual activities, companionship), but agency (e.g., physical fitness, status) was higher in males. Overall expectations and symmetrical reciprocity showed small effect sizes. Medium effect sizes for communion favoring females and for agency favoring males support predictions of evolutionary theory.

Almquist, Ostberg, Rostila, Edlinq and Rydgren (2011) examined friendship network characteristics and psychological well-being in late adolescence by exploring differences by gender and gender composition among Swedish Adolescents born in 1990. The results indicate that males' and females' friendship networks were similar with regard to quality and trust, whereas males' networks were characterized by less self-disclosure and a stronger preference for same-gender friendships. Gender composition did not matter for the support levels. Emotional support was associated with psychological well-being but there were gender differences: females seemed to benefit more health-wise from having high-quality (and trusting) networks. Moreover, whereas self-disclosure among males was positively linked to well-being, this was not the case among females. None of these associations were moderated by gender composition. The study concluded in sum that friendship networks are beneficial for the psychological well-being among late adolescents, but there are some important differences according to gender.

Felmlee and Mraco (2009) examined same and cross-gender friendship norms in a sample of 135 adults (average age 73 years). Participants evaluated a friend's behavior, quantitatively and qualitatively, in vignettes in which the friend's gender was experimentally manipulated. Gender often significantly, though modestly, influenced normative evaluations. Women frequently had higher expectations of friends than men and placed a greater emphasis on intimacy. Women were more disapproving of violations of friendship rules, such as betraying a confidence, paying a surprise visit, and failing to stand up for a friend in public. However, both men and women were less approving of a man than a woman who greets another friend with a 
kiss or who requests to stay overnight. Respondents' open-ended comments reflected positive attitudes regarding cross-gender friendships. Most findings demonstrated that men and women across a wide age range held similar cultural norms for close ties, norms of trust, commitment, and respect.

Afifi and Metts (1998) examined characteristics and consequences of expectation violations in close relationships. The study review relevant extant studies and conclude that research on expectation violations in relationships has adopted a conceptual framework of violations that constrains our understanding of the role that unexpected behaviors play in relationships. First, the relational literature has generally studied extreme and highly salient violations in relationships. Second, much of the research on relationship violations has considered only negatively valence behaviours. Third, violations have almost universally been assumed to increase uncertainty states. Finally, the available evidence about violations in relationship has been descriptive, rather than based on theoretical foundations. In order to address these four concerns, three studies of violations in relationships were conducted. The results (i) provide a typology of expectation violations in close relationships, (ii) confirm that relationship violations vary in intensity, valence and effect on uncertainty, and (iii) support the theoretical logic discussed in Afifi and Burgoon (1996) to predict the relationship outcomes of expectation violations

Cupach and Carson (2002) focusing on characteristics and consequences of interpersonal complaints associated with perceived face threat proposes that recipients' aversive reactions to complaints are a function of perceived face threat. One hundred and ninety-nine college students completed a survey asking them to describe in detail a recent complaint they had received from a friend or romantic partner, and to describe their response to that complaint. Respondents completed measures designed to assess their reactions to the complaint, including perceived face threat, negative affect, fairness, and damage to the relationship. As predicted, dispositional complaints were perceived to be more face threatening than nondispositional complaints, and complaints delivered in public were more face threatening than complaints delivered in private. Both positive and negative face threat were associated with the complaint recipient's anger/hurt and defensiveness. Perceptions of positive face threat also were associated with perceptions of less fairness and greater perceived damage to the relationship, whereas perceived threat to negative face predicted the recipient's feelings of embarrassment and anxiety/depression. The findings indicate that the face-threatening nature of complaints is associated with adverse relational consequences. Perceived threats to positive face, which tend to convey relational devaluation, were more strongly associated with relational damage than were threats to negative face.

Neziek (1995) investigated social construction, gender/sex similarity and social interaction in close Personal relationships. In this study participants maintained a social interaction diary, a variant of the Rochester Interaction Record, to describe their close personal relationships. Relationships were defined using relative frequency of contact with different individuals and via participants' descriptions of relational partners. Individuals with whom participants had more contact were more likely to be described as close friends than were individuals with whom participants had less contact. The results suggest that the characteristics of same-sex relationships depend less on the specific partners composing the relationship than do the characteristics of opposite-sex relationships. As hypothesized, the characteristics of close same-sex relationships did not differ from the characteristics of other same-sex relationships, although interactions with best friends were more intimate than interactions with other samesex partners. In contrast, the characteristics of close opposite-sex relationships differed from the characteristics of other opposite-sex relationships. Men and women who were romantically 
involved had more contact with their romantic partners than with other opposite-sex persons, and they had more contact with their romantic partners than men and women who were not romantically involved had with their most frequent opposite-sex interaction partner. For women, interactions with most frequent opposite-sex interaction partners were more affectively rewarding and instrumentally positive if these men were romantic partners, whereas for men, the affective quality and instrumentality of interactions with most frequent opposite-sex interaction partners did not differ as function of whether these women were romantic partners.

\section{METHOD}

Survey research method involving the use of questionnaire was used for the study. Questionnaire on Ethnic Affiliation was designed for the study. Respondents were requested to provide information on their age, department in the university, and their ethnic group. A list comprising the major ethnic groups and the minority groups in Southern Nigeria suggested by the students was provided. The ethnic groups are Yoruba, Hausa, Igbo, Fulani, Efik, Ijaw, Edo, Itshekiri, "any other". They were asked to indicate the ethnic group they preferred to relate within the following capacities: a) spouse b) close friend c) ordinary friend d) acquaintance e) roommate f) employee in a four man firm g) someone with whom to share apartment or flat h) neighbour i) visitor in house.

\section{Participants}

Participants for the study were drawn from University of Lagos, a Federal university situated in Lagos, a mega city with people of diverse ethnic groups. A total of 684 undergraduate students participated in the study 284 were male while 400 were female. 377 of them belong to the Yoruba ethnic group, 157 were of Igbo origin while the remaining 150 belong to all the other ethnic groups in Nigeria. Their age range was 18 to 34 and they were drawn from all the faculties in the institution.

\section{Procedure}

The questionnaires were administered to the students in lecture rooms and hostels with the help of psychology students. Each student was given a copy of the questionnaire and requested to fill it and return on completion

\section{RESULTS}

The number of respondents of the various listed ethnic groups in Nigeria was calculated. The result show that 377 were of Yoruba origin, 157 Igbo while the remaining 150 belong to other ethnic groups in Nigeria. Consequently, respondents were classified into three categories namely; Yoruba, Igbo and 'any other'. 


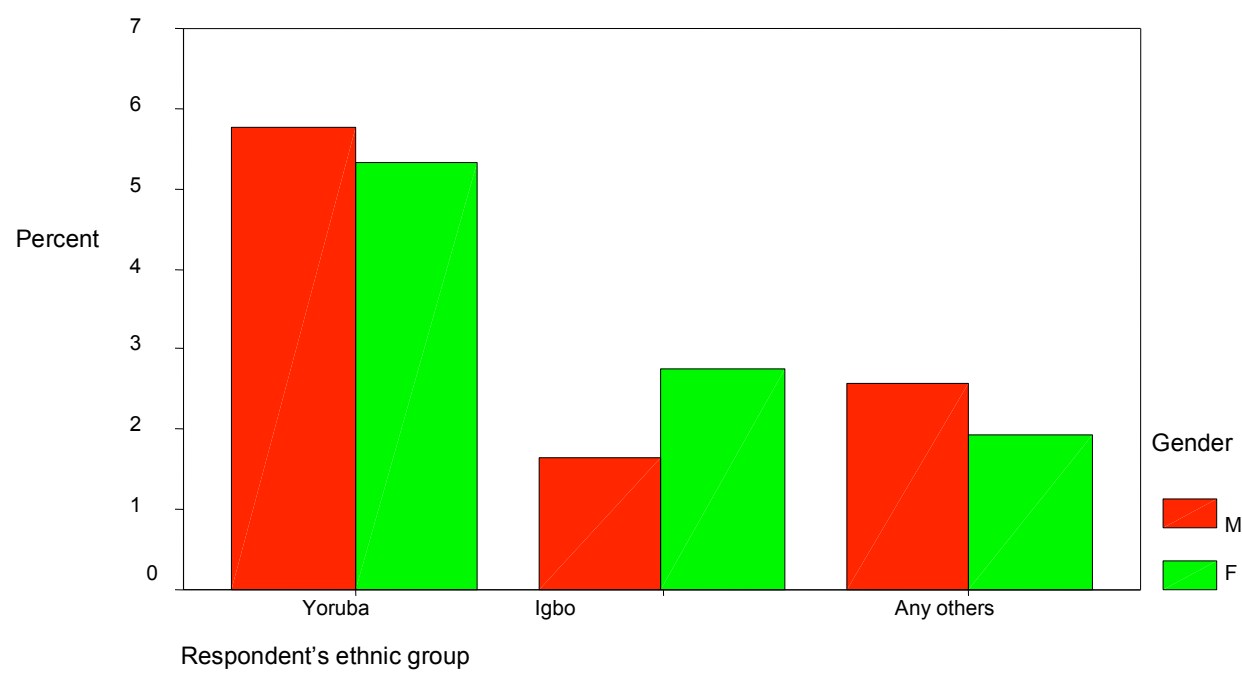

Fig 1 Percentage Distribution of Participants by their Gender and Ethnic Affiliations

Pearson Chi-square was used to compare the number of respondents in the three groups who indicate preference for interactions with persons of the three different groups. Table 1 shows the frequencies and the Chi2 obtained for each of the 9 types of interactions.

TABLE 1: Preference by Respondents' Ethnic Groups

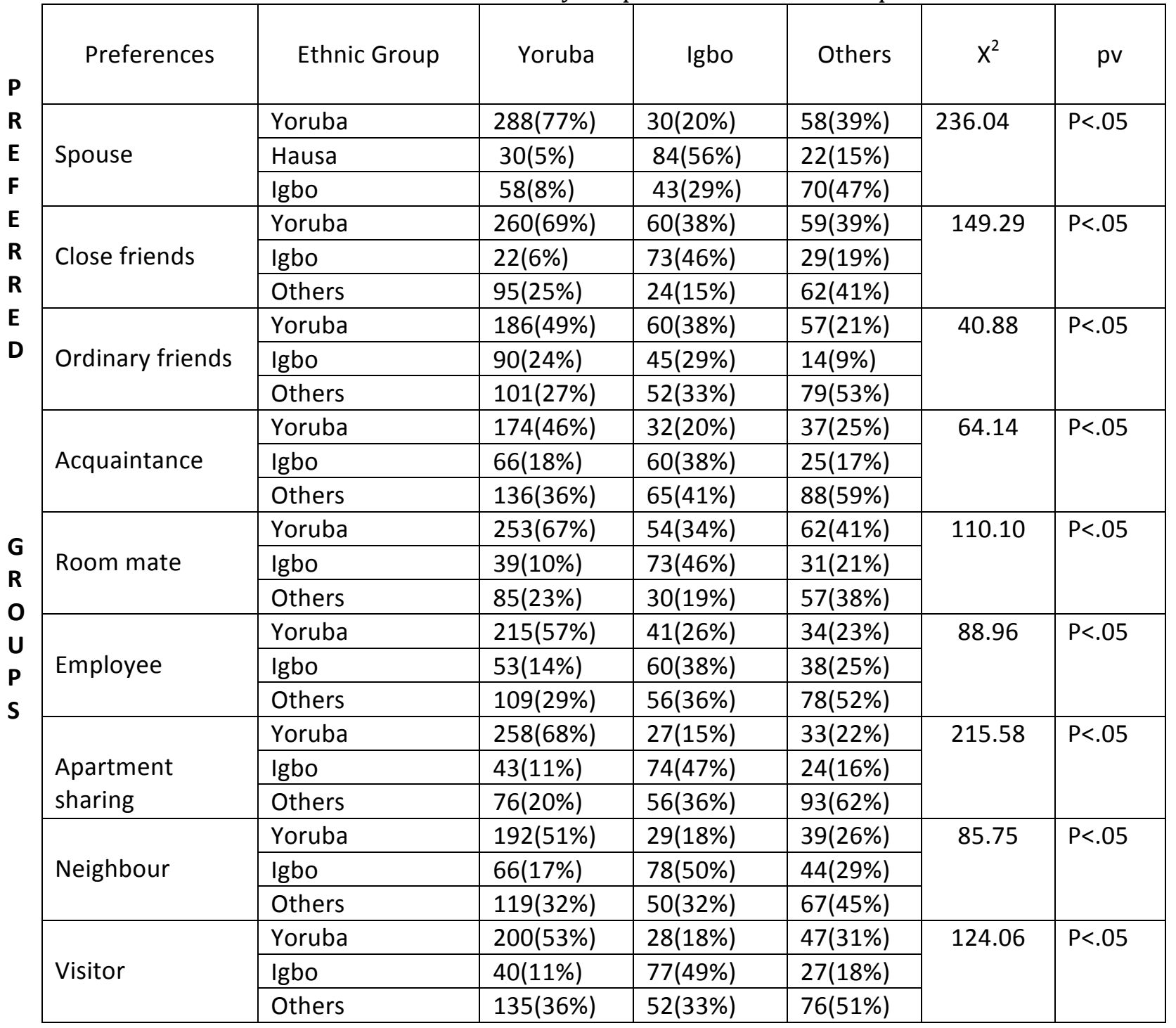


Table 1 shows significant influence of ethnic group on the preferences of respondents for all the types of interactions. It also revealed that more Yoruba respondents show preference for interactions with members of their ethnic group than other ethnic groups. On the other hand, Igbo respondents show preference for their own ethnic group in 7 out 9 categories of interactions. The exceptions are 'spouse' where more of them prefer Hausa and 'close friend' where more show preference for Yoruba. In addition, Hausa was not represented in the sample. Further analysis of spousal preference by gender was carried out. The result is presented in Table 2 .

Table 2 on next page shows that most of the Yoruba's respondents (both male and female) preferred intra-ethnic marriages, However, the percentage was higher for the female (8 1\%) than the male $71 \%$ ) Only $17 \%$ of the male and $15 \%$ of the female indicate preference for Igbo spouses (interethnic marriages).

TABLE 2: Spousal Preferences by Gender Preferred Ethnic Group

\begin{tabular}{|c|c|c|c|c|c|c|}
\hline \multirow{7}{*}{$\begin{array}{l}\text { Respondents } \\
\text { ethnic } \\
\text { groups }\end{array}$} & & & Yoruba & Igbo & Hausa & Total \\
\hline & \multirow[t]{2}{*}{ Yoruba } & Male & $116(71 \%)$ & 27 (17\%) & 20 (12\%) & 163 \\
\hline & & Female & $172(81 \%)$ & 31 (15\%) & $10(5 \%)$ & 213 \\
\hline & \multirow[t]{2}{*}{ Igbo } & Male & $6(13 \%)$ & 7 (15\%) & 34 (72\%) & 47 \\
\hline & & Female & $24(22 \%)$ & $36(33 \%)$ & $50(45 \%)$ & 110 \\
\hline & \multirow[t]{2}{*}{ Others } & Male & $22(30 \%)$ & 41 (56\%) & $10(14 \%)$ & 73 \\
\hline & & Female & 36 (47\%) & $29(38 \%)$ & $12(16 \%)$ & 77 \\
\hline
\end{tabular}

Furthermore $12 \%$ of the male and $5 \%$ of the female preferred. A high percentage $(72 \%)$ of the male Igbo respondents indicate preference for Hausa spouses while only $45 \%$ of their female counterparts stated they preferred Hausa spouses. Only 13\% of the Igbo male indicate preference for Yoruba spouses while 24\% of the female show preference for Yoruba as husbands thus showing that more female than male Igbo preferred Yoruba spouses.. Preference for intra-ethnic marriages was higher for the female Igbo(33\%) than for their male counterparts(15\%). However, only 5\% female respondents preferred intra-Hausa ethnic marriages. As for the remaining respondents that were classified as 'others', $30 \%$ of the males and $47 \%$ of the females preferred Yoruba spouses. The reverse was the case for preference for Igbo spouses with $56 \%$ male and $38 \%$ female showing preference for Igbo.

Further, in order to investigate the influence age, gender and ethnic affiliations on ethnic tolerance as measured by the frequencies of inter-ethnic preferences under investigation, Logistic regression analysis was computed using frequencies of inter-ethnic preferences as levels of ethnic-tolerance index (dependent variables). The result is presented in Table 3.

Table 3: Summary Table of Logistic Regression Analysis

\begin{tabular}{|c|c|c|c|c|c|c|c|c|}
\hline \multirow{2}{*}{ VARIABLES } & \multicolumn{6}{|c|}{ VARIABLES IN THE EQUATION } & \multicolumn{2}{|c|}{ 95\% Cl for Exp. (B) } \\
\hline & B & SE & Wald & $\mathrm{df}$ & Sig. & Exp.(B) & Lower & upper \\
\hline Age (Young/old Adults) & .3143 & .0201 & .0532 & 1 & .0312 & 3.076 & .1120 & 3.076 \\
\hline Gender (Male/female) & .2341 & .2098 & .0237 & 1 & .0432 & 4.257 & .1003 & 4.846 \\
\hline Ethnic (Yoruba/Igbo) & .3324 & .4011 & .0312 & 1 & .0510 & 6.345 & .1240 & 6.345 \\
\hline $\begin{array}{l}\text {-2 Log Likelihood } \\
\text { Cox \& Snell - } \text { R }^{\wedge}\end{array}$ & \multicolumn{8}{|c|}{$\begin{array}{l}569.428 \\
322.209\end{array}$} \\
\hline
\end{tabular}

Results of Logistic regression as presented in Table 3 revealed a significant positive progression in the observed ethnic tolerance. This implies that young adults were about 3.07 
times more tolerant of other ethnic groups than their old adult's counterparts. Similarly, males reported about 4.25 times more tolerance to ethnic differences compared to their female counterparts. Also, Yoruba participants reported about 6.34 times more tolerant to other ethnic groups compared to both Igbo's and the other ethnic groups. This result is very instructive with far reaching implications for structuring enduring inter-ethnic interpersonal relationship. The results inter-alia revealed that despite the fact both Yoruba's, Igbo's and other ethnic groups preferred somebody of their ethnic group as spouse, close friend, ordinary friend, room-mates, employees, neighbours and visitors, Yoruba's reported a much better openness and ethnic tolerance, followed closely by Igbo's and other ethnic enough groups (i.e. Fulani's, Hausa's, Tiv's, Ijaw's, Efik's etc). This result is rather surprising because the fact the Igbo's and Yoruba's are widely travelled and are found almost in any town or villages in Nigeria, is reason to expect that their level of tolerance for other ethnic groups should be very high.

\section{DISCUSSION}

The results of this study reveal that respondents showed preference for interaction with members of their own ethnic groups than other ethnic groups, irrespective of the type of interaction. This should be of great concern because lack of interaction could hinder the unity which is essential for the development. The results also show that more of the Yoruba respondents preferred interactions with members of their own group. This is likely due to the peculiarity of this group; they might not have enough experience with other groups by virtue of the fact that they are schooling in the geographical location of their ethnic group. On the other hand, the Igbo respondents show preference for Yoruba close friends and spouses. This can be attributed to their schooling in south-west where there are more of the Yoruba ethnic group thereby having opportunity to interact with them. Such proximity has been known to encourage interpersonal attraction. This result is consistent with that of Argyle (1983) which reported that the more two people interact, the more polarised their attitudes towards each other become - usually in the direction of greater liking. This, in turn, increases the likelihood of further interaction, but only if the interaction is on an equal footing. The result also amplifies Fujino (1997) findings that people form friendships with those they encounter frequently (as the mere exposure effect would predict). Kubitschek and Hallinan (1998) findings that person's of different cultural background are more likely to date themselves when they are in close proximity and high-school students form friendships within their own academic subjects is not consistent with the present findings in Nigeria. Moreover, the finding is consistent with that of Jeffrey (2011) in a similar study investigated sex differences in friendship expectations. The study contends that friendship expectations are prescriptive normative behaviours and highly valued qualities in ideal same-sex friends. Dugan and Kivett (1998) findings that older adults that relocated make friends among their nearest neighbours is also refuted.

The findings of this study also include male preference for inter-ethnic marriages and female preference for intra-ethnic marriages. This is largely due to the fact that marriage in Nigeria involves the man assimilating the woman into his extended family. This result is consistent with the assumptions envisaged in the Kerckhoff and Davis (1962) assumption that individual' psychological characteristics (agreement on basic values) predicted probability of relationship becoming more stable and permanent. Moreover, the result also supported Kerckhoff and Davis (1962) that complementarity of emotional needs predicted long term commitment. Complementary behaviours take account of each other's needs, helping to make a perfect whole and the relationship feel less superficial (Duck, 1999). These findings underscores the continue relevance of provision of all policy initiatives for youths to interact and appreciate the various ethnic groups to foster unity. It has therefore become a matter of outmost concern that 
all hands must be on deck for reducing the boundaries and social distances between the peoples of various ethnic groups. It is worth noting that there was no Hausa respondent among the sample. This shows that this group may be few in the university despite the fact that it is a federal institution. This may be due to the far distance between the northern and the southern part of the country.

\section{CONCLUSIONS}

One of the salient findings was that sampled young adults showed preference for interaction with members of their own ethnic groups than other ethnic groups, irrespective of the type of interaction. Other findings revealed a very weak inter-ethnic affiliation among young adults, particularly among the Yoruba's, Igbo's and others with grave implications for the quest for inter-ethnic unity among Nigerian young adults. For example, young adults were more tolerant of other ethnic groups than their old adult's counterparts, males reported more tolerance to ethnic differences compared to their female counterparts. Also, Yoruba participants reported are more tolerant to other ethnic groups compared to both Igbo's and the other ethnic groups. Yoruba's, Igbo's and other ethnic groups preferred somebody of their ethnic group as spouse, close friend, ordinary friend, room-mates, employees, neighbours and visitors, Yoruba's reported a much better openness and ethnic tolerance, followed closely by Igbo's and other ethnic enough groups. These findings should be of great concern to local, state and federal government of Nigeria, because lack of interaction could hinder the unity which is essential for the development. This result and similar others reported above seemingly explain the reason why Nigeria ethnographic polarity is effectual. There is no doubt about the fact ethnic intolerance is a major factor in failed national integration efforts of the Federal Government of Nigeria. More than before, the findings have tremendous implication for appropriate policy initiative to forester harmonious inter-ethnic relationship in the country. It has become a matter utmost concern to note that inter-ethnic friendship and the attitudes that Nigerian citizens towards themselves is rather narrowing down. This further underscores the significance of the National Youth Service Corp whereby graduates serve outside their states of origin. It is hereby presumed that this information will be beneficial to the government in terms of raising awareness, building corporate consensus that will effectively contribute to the success of appropriate policy formulation for national integration and youth development.

\section{References}

Argyle, M. (1983). The psychology of interpersonal behaviour. New York: Pelican Penguin Books

Argyle, M. \& Furnham, A. (1983). Sources of satisfaction and conflicts in long-term relationships. Journal of Marriage and Family, 45, 481-493.

Almquist, Y.B., Östberg, V., Rostila, M., Edling, C.R. and Rydgren, J. (2014). Friendship Network Characteristics and Psychological Well-being in Late Adolescence: Exploring Differences by Gender and Gender Composition. Scandinavian Journal of Public Health 42(2), 146-154.

Argyle, (2002). The rules of friendship. Journal of Social \& Personal Relationships,19, 443-462.

Argyle, M. (1987). The psychology of happiness. London: Routledge.

Afifi, W.A., \& Metts, S. (1998). Characteristics and Consequences of Expectation Violations in Close Relationships. Journal of Social \& Personal Relationship, 15, 421-430.

Berscheid, E., \& Amazzalorso, H. (2004). Emotional experience in close relationships. In Brewer, M., B., \& Hewstone, M. (Eds.), Emotion and motivation (pp. 47-69). Malden, MA: Blackwell Publishing. 
Berscheid, E., \& Reis, H. T. (1998). Attraction and close relationships. In D. T.Gilbert, S. T. Fiske, \& G. Lindzey (Eds.), The handbook of social psychology(4th ed., pp. 193-281). Boston: McGraw-Hill.

Buunk, A.P., \& Dijkstra, P. (2008). Affiliation, attraction and close relationships. In M. Hewstone, W. Stroebe \& Jonas, K. (Eds.), Introduction to Social Psychology. (pp. 196-215). Oxford, Blackwell Publishing.

Cupach, W., \& Carson, C.L. (2012). Characteristics and consequences of interpersonal complaints associated with perceived face threat., Journal of Social \& Personal Relationship, 19, 443-462.

Clore, G. L., \& Byrne, D. (1974). The reinforcement-affect model of attraction. In T. L. Huston

(Ed.), Foundations of interpersonal attraction (pp. 143-170). New York: Academic Press.Duck, (1988).

Duck, S. W. (1999). Relating to others. (2 ${ }^{\text {nd }}$ Edition). Milton: Open University Press

Dugan, E. \& Kivett, V.R. (1998). Implementing the Adams and Blieszner conceptual model: Predicting

interactive friendship processes of older adults. Journal of Social Personal Relationships, 15(5), 607-622.

Felmlee, D \& Muraco, A. (2009). Gender and friendship norms among older adults. Research on Aging, 31, 318-344.

Felmlee, D.H. (2001). From appealing to appalling: Disenchantment with a romantic partner. Sociological Perspectives, 44, 263-280.

Festinger, L., Schachter, S., \& Back, K. (1950). Social Pressures in Informal Groups, New York: Harper and Brothers.

Fiske, S. T. (2004). Social beings: A core motives approach to social psychology. New York: Wiley.

Fujino, D. C. 1997). The rates, patterns, and reasons for forming heterosexual inter-racial dating relationships among Asian Americans. Journal of Social \& Personal Relationships, 14(6), 809-828.

Gruder, C. L. (1971). Determinants of social comparison choices. Journal of Experimental Social Psychology, $7(5), 473-489$.

Heider, F. (1958). The psychology of interpersonal relations. New York: John Wiley \& Sons.

Holmes, J. G. (2000). Social relationships: The nature and function of relational schemas. European Journal of Social Psychology, 30, 447-495.

Jeffrey, A. (2002). Friendship standards: The dimensions of ideal expectations. Journal of Experimental Social Psychology, 28, 884-907.

Jeffrey, A. (2011). Sex differences in friendship expectations: A Meta-Analysis. Journal of Social \& Personality Psychology, 28, 723-747.

Kelley, H. H., Berscheid, E., Christensen, A., Harvey, J. H., Huston, T. L., Levinger, G., McClintock, E., Peplau, L. A., \& Peterson, D. R. (1983). Close relationships. New York: Freeman.

Kerckhoff, A.C.\& Davis, K. E. (1962). Value consensus and need complementarity in mate selection. American Sociological Review, 27, 295-303.

Kerckhoff, A. C. (1974). Ambition and attainment. Washington DC. American Sociological Association, Arnold Caroline Rose Monograph Series.

kivett, V. R. (1988). Older rural fathers and sons: Pattern of association and helping. Family Relations, 37, 62-67.

Kubitschek, W., \&. Hallinan, M.T. (1996). Race, gender and inequity in track assignments. In Pallas, A. (Ed.), Research in Sociology of Education and Socialization, 11, 121-146. Greenwich CT: JAI Press.

Kulik, J. A., \& Mahler, H. I. M. (1989). Social support and recovery from surgery. Health Psychology, 8, 221-238.

Kulik, C., E. L. Perry, et al. (2003). "Here Comes Th Judge: The Influence of Judge Personal Characteristics on Federal Sexual Harrassment Case Outcomes." Law and Human Behavior 27(1): 69-86. 
Lott, B. E., \& Lott, A. J. (1974). The role of reward in the formulation of positive interpersonal attitudes. In T. L. Huston (Ed.), Foundations of interpersonal attraction (p. 171-192). New York: Academic Press.

Moghaddam, FM, Taylor, DM \& Wright SC (1993) Social Psychology in Cross-Cultural Perspective, quoted in Gross, R.D (1995) Themes, Issues and Debates in Psychology, London: Hodder \& StoughtonMurstein, B. I. (1987). Clarification and extension of the SVR theory in diadic pairing. Journal of Marriage and the Family, 49(4), 929-933.

Neziek, J. B. (1995). Social Construction, Gender/Sex Similarity and Social Interaction in Close Personal Relationships. Journal of Social \& Personal Relationship, 12, 503-520.

Wills, T. A. (1981). Downward comparison principles in social psychology. Psychological bulletin, 90(2), 245.

Zajonc, R. B. (1968). Attitudinal effects of mere exposure. Journal of Personality \& Social Psychology, 9(2), 1-27. 